\title{
Protruded duodenal tumor arising from Santorini's duct of the pancreas: a rare case of intraductal papillary mucinous neoplasm mimicking a duodenal polypoid tumor
}

Haruna Komatsubara ${ }^{1,2}$, Hiroyuki Kato ${ }^{1,2^{*}}$, Daisuke Noguchi ${ }^{1,2}$, Kazuyuki Gyoten $^{1,2}$, Aoi Hayasaki ${ }^{1,2}$, Yusuke lizawa ${ }^{1,2}$, Takehiro Fujii ${ }^{1,2}$, Akihiro Tanemura ${ }^{1,2}$, Yasuhiro Murata ${ }^{1,2}$, Naohisa Kuriyama ${ }^{1,2}$, Masashi Kishiwada ${ }^{1,2}$, Hiroyuki Sakurai ${ }^{1,2}$ and Shugo Mizuno ${ }^{1,2}$

\begin{abstract}
Background: We experienced a rare case of intraductal papillary mucinous neoplasm arising from Santorini's duct (SD) forming a tumor protruding into the duodenum .

Case presentation: A 71-year-old woman was incidentally diagnosed with a $3 \mathrm{~cm}$ type Isp polypoid tumor in the second portion of the duodenum at another hospital. Enhanced CT and endoscopic ultrasound revealed that the origin of this protruding tumor was arising from SD and that the tumor mimicked a pedunculated duodenal tumor. Our preoperative diagnosis was a malignant pancreatic tumor arising from SD with invasion into the duodenum. She underwent a subtotal stomach-preserving pancreaticoduodenectomy, and the resected specimen showed a $25 \mathrm{~mm}$ tumor protruding into the duodenum with a villous surface. The pathological findings revealed that the tumor was intraductal papillary mucinous adenoma (IPMA) arising from SD.
\end{abstract}

Conclusions: To the best of our knowledge, this is the first case of IPMA protruding into the duodenal lumen from SD, although most of the tumors arising from SD have been reported to be malignant.

Keywords: Duodenal tumor, Santorini's duct, Intraductal papillary mucinous neoplasm

\footnotetext{
*Correspondence: katohiroyuki510719@gmail.com

'Department of Hepatobiliary Pancreatic and Transplant Surgery, Graduate

School of Medicine, Mie University, 2-174 Edobashi, Tsu, Mie 514-0001, Japan

${ }^{2}$ Department of Hepatobiliary Pancreatic and Transplant Surgery, Mie

University, Tsu, Japan
}

(c) The Author(s). 2020 Open Access This article is licensed under a Creative Commons Attribution 4.0 International License, which permits use, sharing, adaptation, distribution and reproduction in any medium or format, as long as you give appropriate credit to the original author(s) and the source, provide a link to the Creative Commons licence, and indicate if changes were made. The images or other third party material in this article are included in the article's Creative Commons licence, unless indicated otherwise in a credit line to the material. If material is not included in the article's Creative Commons licence and your intended use is not permitted by statutory regulation or exceeds the permitted use, you will need to obtain permission directly from the copyright holder. To view a copy of this licence, visit http://creativecommons.org/licenses/by/4.0/ The Creative Commons Public Domain Dedication waiver (http://creativecommons.org/publicdomain/zero/1.0/) applies to the data made available in this article, unless otherwise stated in a credit line to the data. 


\section{Background}

Duodenal neoplasms are rare entities accounting for less than $1 \%$ of all gastrointestinal tumors and are characterized by their location in the duodenum and proximity to the ampulla [1]. On the other hand, duodenal polyps are found in 1.5-4.6\% of routine esophagogastroduodenoscopy (EGD) procedures and 7\% are reported to be diagnosed as adenoma [2]. The current treatment options for duodenal tumors include open surgical resection and endoscopic techniques such as endoscopic mucosal resection and submucosal dissection, but a precise treatment strategy has yet to be established.

Furthermore, the increased detection rate of pancreatic cysts due to the improvements and increases in the number of imaging studies has led to a surge in interest in intraductal papillary mucinous neoplasms (IPMNs) of the pancreas. IPMNs are usually classified into three types based on imaging studies and/or histology based on the origin of the tumor whether it arises from the main pancreatic duct (MPD), branches of the main ductal system, or both of them. According to these classifications, the treatment strategy was varies from conservative observation to pancreatic resection.

Regarding the location of pancreatic IPMNs, Santorini's duct (SD) is rarely the origin of IPMNs [3, 4]. Moreover, there has been no report in which an IPMN originating from SD protruded from the minor papilla, mimicking a duodenal polypoid tumor. We herein report a rare case of an IPMN arising from SD, forming a duodenal pedunculated tumor. To the best of our knowledge, this is the first case report of a protruded duodenal polypoid tumor.

\section{Case presentation}

A 71-year-old woman was incidentally diagnosed with diabetes mellitus with an elevated HbA1c, and a multimodal assessment was conducted to search for its cause. Her medical history included acute pancreatitis of unknown etiology and laparoscopic cholecystectomy for gallstones. Abdominal computed tomography (CT) in another hospital showed a mass lesion in the second portion of the duodenum and dilation of the main pancreatic duct (MPD). Gastroduodenal endoscopy incidentally showed a $3 \mathrm{~cm}$ type Isp polypoid tumor in the second portion of the duodenum (Fig. 1a) and slight mucin production from the major papilla (Fig. 1b). Thus, she was referred to our hospital for further evaluation. The endoscopic tumor biopsy showed papillarytubular neoplasm with low grade dysplasia, but she was not diagnosed with a malignancy based on the degree of cellular atypia. On admission, her serum amylase level was $203 \mathrm{U} / \mathrm{L}$, HbA1c was $12.4 \%$ and other biochemical data were within the normal range. Regarding tumor markers, her level of carbohydrate antigen (CA) 19-9 was elevated by $60.2 \mathrm{U} / \mathrm{ml}$, carcinoembryonic antigen (CEA) and duke pancreatic monoclonal antigen type 2 (DUPAN2), which is a serum marker for pancreatic cancer that when elevated, suggest the presence of malignancy, were within a normal range though.

Thin-slice enhanced abdominal CT imaging in our hospital demonstrated an enhanced mass (approximately $25 \mathrm{~mm}$ in size) in the second part of the duodenum, which is adjacent to the dilated SD. The dilated SD also had an enhanced nodule, suggesting an intraductal tumor (Fig. 2a). Endoscopic ultrasound (EUS) revealed a dilated SD and irregular mucosal thickness in its branches. In the region of SD, an ill-defined low echoic area that continuously extended to a pedunculated tumor at the orifice of the minor papilla was discovered (Fig. 2b). Endoscopic retrograde cholangiopancreatography delineated the entire main pancreatic duct, but SD
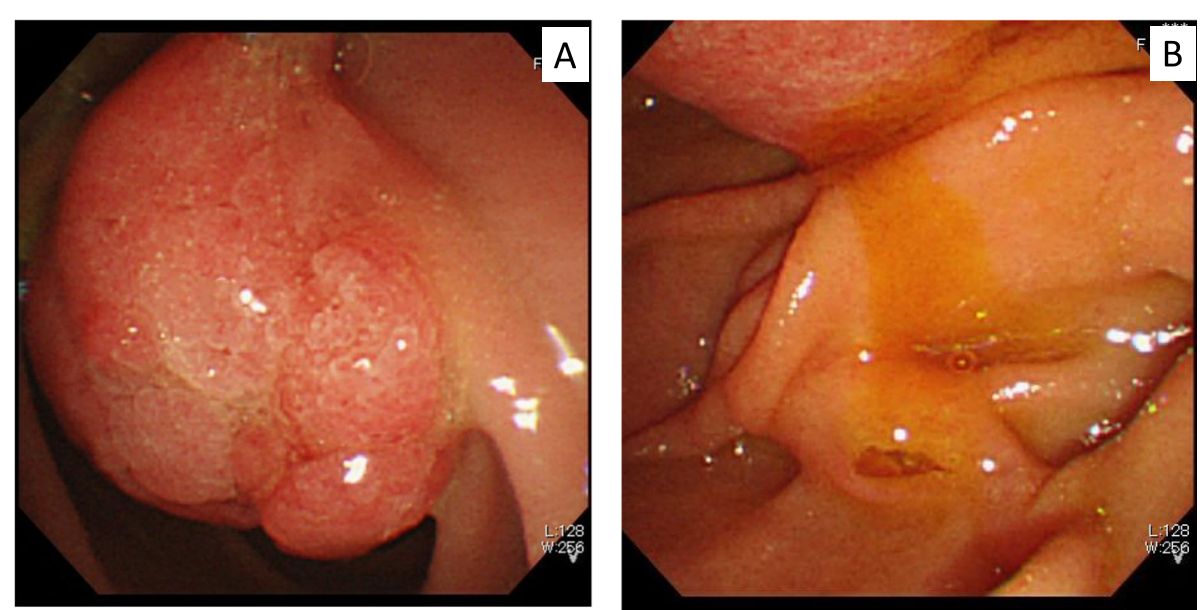

Fig. 1 Gastroduodenal endoscopy findings. A polypoid tumor is located at the second portion of the duodenum (a). The orifice of the major duodenal papilla is mildly enlarged, and slight mucin production is seen (b) 

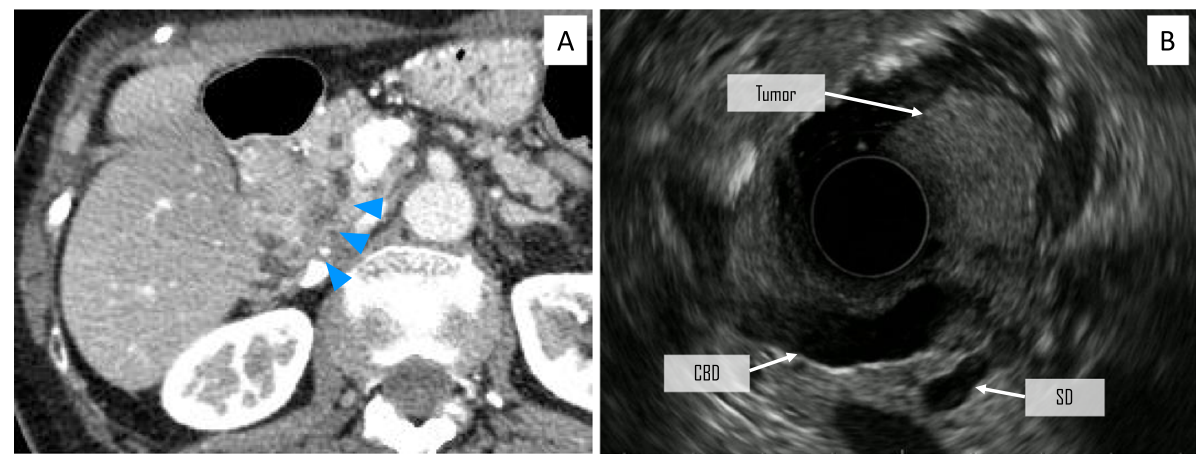

Fig. 2 Preoperative imaging studies. Contrast-enhanced abdominal CT imaging demonstrates an enhanced mass in the second part of the duodenum, which is adjacent to the dilated SD (arrowhead) (a). Radial EUS showed that the tumor protruded into the duodenum from the SD (b). CT: computed tomography, EUS: endoscopic ultrasound, SD: Santorini's duct, CBD: common bile duct

was not well delineated as shown in Fig. 3. The preoperative diagnosis was a malignant pancreatic tumor arising from SD with invasion into the duodenal lumen. She underwent subtotal stomach-preserving pancreaticoduodenectomy and her postoperative course was uneventful.

Macroscopically, the resected specimen showed a 25 $\mathrm{mm}$ duodenal projection with a villous surface (Fig. 4a), which was the same composition as the grossly visible, cylindrically dilated SD (Fig. 4b). Microscopically, the tumors were characterized by the intraductal proliferation of columnar mucin-producing cells, which form papillae ranging from the microscopic fold to grossly visible projections. This tumor had moderate nuclear atypia, and stromal invasion was not observed. In this case, the

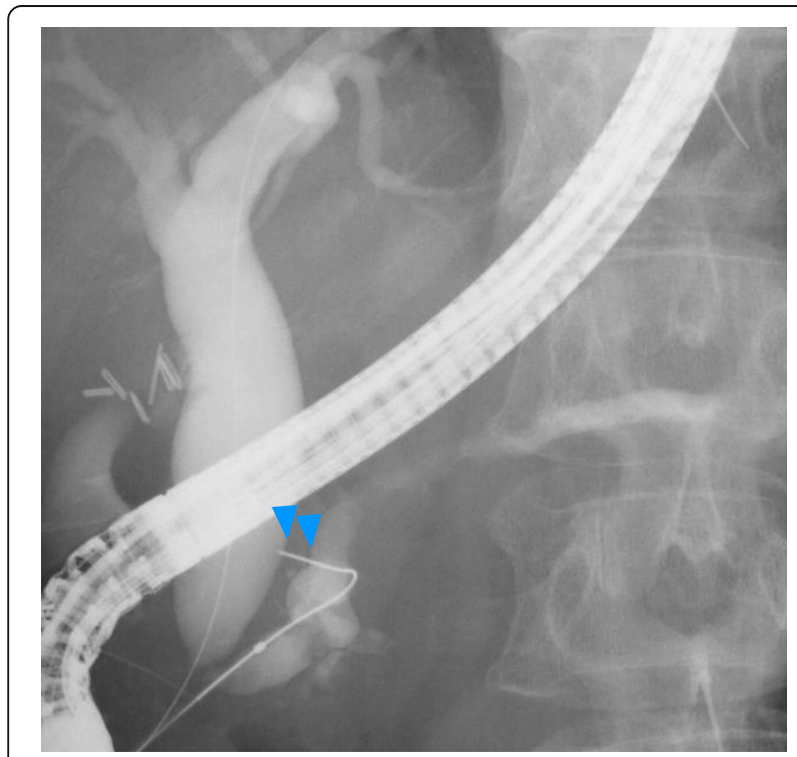

Fig. 3 ERCP delineated the entire main pancreatic duct, but not SD, which might be due to the mucin production from the tumor (arrowheads). ERCP: endoscopic retrograde cholangiopancreatography, SD: Santorini's duct primary focus was recognized to be arising from SD, although the tumor involved not only SD but also its branches. These findings herein led to the diagnosis of an IPMA of the gastric type with intermediate dysplasia (low-grade IPMN in the 5th edition of the WHO tumor classification) originating from $\mathrm{SD}$ and its branches (Fig. 5a and b).

\section{Discussion and conclusions}

In the present case, discrimination between a duodenal polypoid tumor and IPMN was difficult, because a type I papillary polypoid tumor was seen in the second portion of duodenum by EDG, mimicking a duodenal polypoid tumor. However, EUS revealed that the low echogenicity area continuously extended to a pedunculated tumor at the orifice of the minor papilla, allowing us to make a precise diagnosis preoperatively.

In the differential diagnosis of this unusual IPMN, superficial non-ampullary duodenal tumors (SNADET), which are defined as lesions that are limited to the duodenal mucosa or submucosa, including adenoma and/or adenocarcinoma was regarded as one of the possible diagnoses. SNADETs are grossly classified according to the Paris endoscopic classification, and the gross morphology is classified based on endoscopic findings and divided into pedunculated (Ip), sessile (Is), semipedunculated (Isp), superficial elevated (IIa), completely flat (IIb) or superficial shallow or depressed types (IIc) [5]. To treat SNADETs, surgical resection such as limited local resection, endoscopic mucosal resection (EMR) and endoscopic submucosal dissection (ESD) are indicated according to the tumor size [6]. In this case, this polyp seemed to be an Isp SNADET, but the tumor size was larger than $20 \mathrm{~mm}$; thus, endoscopic resection was contraindicated, even if this tumor was assumed to be a SNADET.

To discrimination between anomalous IPMN and SNADET in our case, EUS was very useful for identifying 

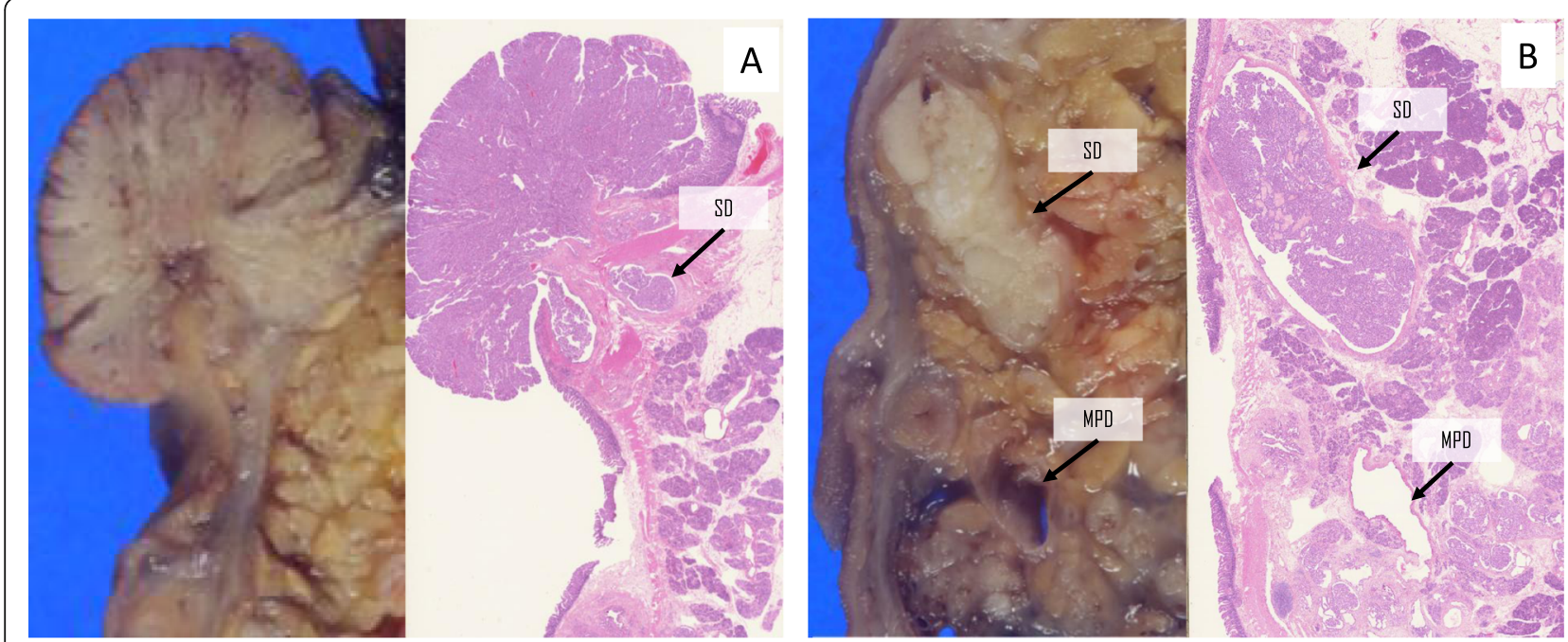

Fig. 4 Macroscopic findings of the resected specimen. The resected specimen shows the tumor protruding into the duodenum, which was adjacent to the dilated SD (a), and a grossly visible intraductal tumor within SD and its branches (b). MPD: main pancreatic duct, SD: Santorini's duct

that this pedunculated polyp was protruding from SD of the pancreas, allowing us to perform the proper surgical treatment for this rare type of tumor.

IPMNs arising in SD or its branches are quite rare, and only 11 cases have been reported in the English literature as shown in Table 1 [7-12]. Among them, 9 cases were considered carcinoma, and only 2 cases were diagnosed as adenoma. With regard to the duodenal tumor formation, only our case shows a tumor arising from SD protruding into the duodenal lumen. Although Miyake et al. [10] reported a patient with tumor formation at the minor papilla of the duodenum, the tumor was a malignant IPMN arising from SD that invaded to the duodenal wall directly, which is different from our case. To the best of our knowledge, this is the first case of an IPMA protruding into the duodenal lumen from SD.

Regarding the prognosis of IPMNs derived from SD, Hirano et al. [7] reported that this type of tumor showed an unfavorable prognosis with compared to that of the tumors arising from the MPD. However, the precise prognosis of these tumors has yet to be elucidated

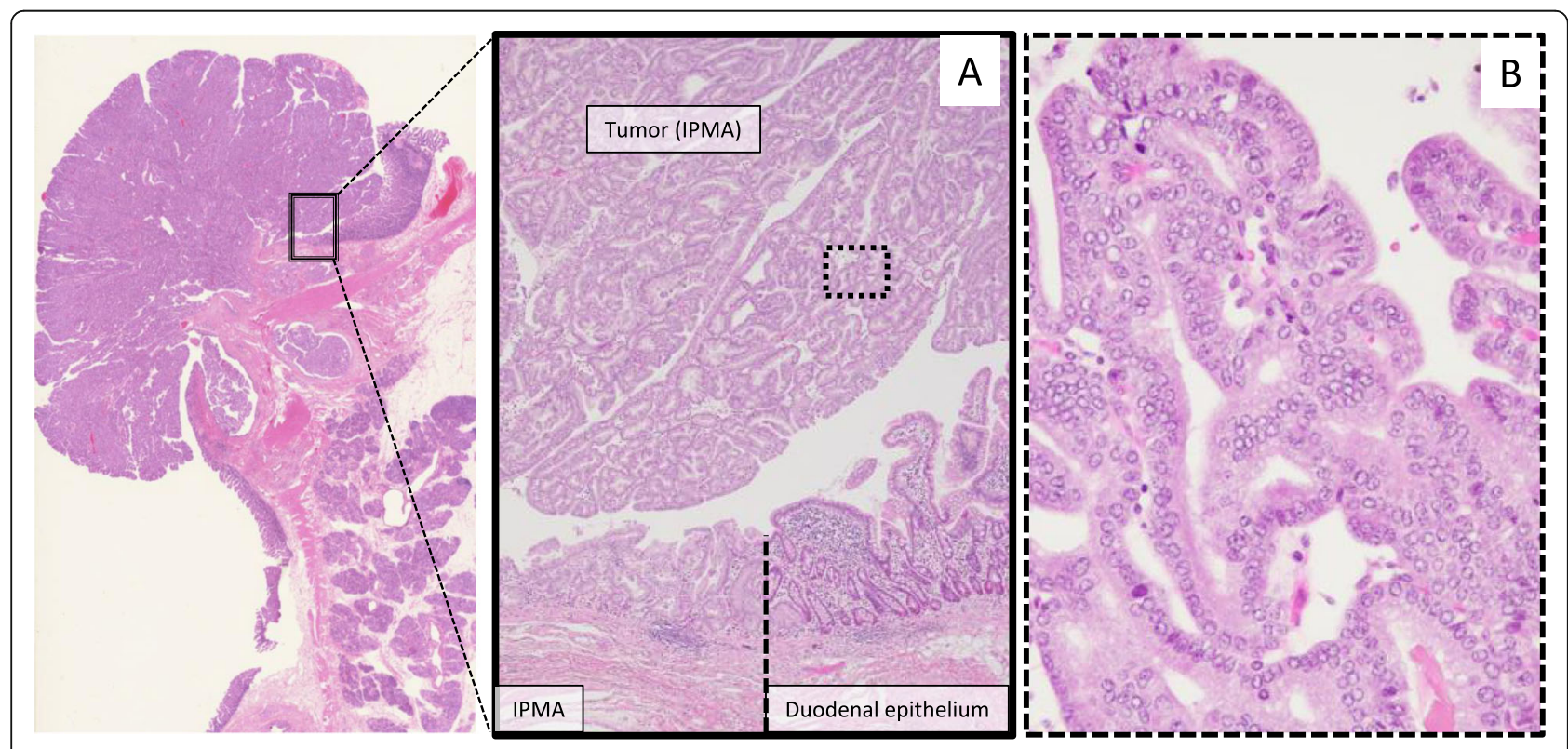

Fig. 5 Microscopic findings of a duodenal tumor. The transition region between the IPMA (left and upper side) and normal duodenal mucosa (right side) (a). This intraductal tumor has intermediate level nuclear atypia (b) and was diagnosed as an IPMA with intermediate dysplasia. IPMA: intraductal papillary mucinous adenoma 
Table 1 Summary of cases of intraductal papillary mucinous neoplasm arising from SD in the literature

\begin{tabular}{|c|c|c|c|c|c|c|c|c|c|}
\hline Case & & Year & Age & Gender & Primary lesion & $\begin{array}{l}\text { Protrusion to } \\
\text { duodenal lumen }\end{array}$ & $\begin{array}{l}\text { Operative } \\
\text { procedure }\end{array}$ & $\begin{array}{l}\text { Pathological } \\
\text { diagnosis }\end{array}$ & $\begin{array}{l}\text { Prognosis } \\
\text { (months) }\end{array}$ \\
\hline 1 & Saito 9) & 1989 & 74 & $\mathrm{~F}$ & SD & - & inoperable & $\begin{array}{l}\text { adenocarcinoma } \\
\text { with liver metastasis }\end{array}$ & 4 (dead) \\
\hline 2 & Miyake 10) & 2004 & 67 & M & SD & - & SSPPD & Adenocarcinoma* & ND \\
\hline 3 & Kanazumi 11) & 2004 & 71 & M & SD & - & PPPD & adenocarcinoma & 13 (alive) \\
\hline 4 & Hirano 2) & 2005 & 60 & M & SD & - & PD & adenocarcinoma & ND \\
\hline 5 & Hirano 2) & 2005 & 73 & $\mathrm{~F}$ & SD & - & DPPHR & adenocarcinoma & ND \\
\hline 6 & Hirano 2) & 2005 & 66 & M & Branch of SD & - & PPPD & adenocarcinoma & ND \\
\hline 7 & Hirano 2) & 2005 & 46 & $\mathrm{~F}$ & SD & - & PRPD & adenocarcinoma & ND \\
\hline 8 & Akashi12) & 2013 & 78 & $\mathrm{~F}$ & Branch of SD & - & PD & $\begin{array}{l}\text { adenocarcinoma with } \\
\text { cholangiocarcinoma }\end{array}$ & $\begin{array}{l}59 \text { (dead for } \\
\text { other illness) }\end{array}$ \\
\hline 9 & Abe 7) & 1998 & 65 & M & Branch of SD & - & PD & $\begin{array}{l}\text { adenoma with } \\
\text { carcinoma of } \\
\text { cystic duct }\end{array}$ & 15 (alive) \\
\hline 10 & Hirano 8) & 2005 & 63 & $\mathrm{~F}$ & Branch of SD & - & DPPHR & adenoma & ND \\
\hline 11 & our case & & 71 & $\mathrm{~F}$ & SD & $+(25 \mathrm{~mm})$ & SSPPD & adenoma & 14 (alive) \\
\hline
\end{tabular}

SD Santorini's duct, SSPPD Subtotal stomach-preserving pancreaticoduodenectomy, PD Pancreaticoduodenectomy, DPPHR Duodenum-preserving pancreas head resection, PPPD Pylorus-preserving pancreaticoduodenectomy, PRPD Pylorus-resecting pancreatoduodenectomy, ND not described

* Showing direct duodenal invasion

because of the small number of patients, insufficient follow-up period, and variations in tumor differentiation from adenoma to adenocarcinoma. Therefore, more cases need to be accumulated to elucidate the clinicopathological characteristics and prognosis of these tumors.

We experienced a rare case of an IPMA protruding into the duodenal lumen from SD, although most of the tumors arising from SD have been reported to be malignant.

\author{
Abbreviations \\ EGD: Esophagogastroduodenoscopy; IPMN: Intraductal papillary mucinous \\ neoplasm; MPD: Main pancreatic duct; CT: Computed tomography; CA19- \\ 9: Carbohydrate antigen 19-9; CEA: Carcinoembryonic antigen; \\ DUPAN2: Duke pancreatic monoclonal antigen type 2; EUS: Endoscopic \\ ultrasound; SNADET: Superficial non-ampullary duodenal tumors; \\ SD: Santorini's duct; CBD: Common bile duct; IPMA: Intraductal papillary \\ mucinous adenoma; SSPPD: Subtotal stomach-preserving pancreaticoduode- \\ nectomy; PD: Pancreaticoduodenectomy; DPPHR: Duodenum-preserving \\ pancreas head resection; PPPD: Pylorus-preserving \\ pancreaticoduodenectomy; PRPD: Pylorus-resecting \\ pancreatoduodenectomy; ND: Not described
}

\section{Acknowledgements}

We are grateful for the patient for giving consent of publication, and we thank the all research staff involved in this case study.

\section{Authors' contributions}

HK1 has made the draft of this manuscript and HK2 and SM substantively revised it. The drafts of the figures and tables were made by DN and KG. YI, TF, AT, YM, NK, and AH expended much effort in acquiring clinical data, histological findings, and interpretative reports. MK and HS were tasked with important intellectual content revisions. All authors have read and approved the final manuscript. * HK1 corresponding to Haruna Komatsubara, and HK2 corresponding to Hiroyuki Kato.

\section{Funding}

None to declare.
Availability of data and materials

All data generated or analyzed during this study are included in this published article.

\section{Ethics approval and consent to participate}

Not applicable.

\section{Consent for publication}

Written informed consent was obtained from the patient herself for publication of this case report and any accompanying images. A copy of the written consent is available for review by the Editor of this journal.

\section{Competing interests}

The authors declare that they have no competing interests.

Received: 27 March 2020 Accepted: 11 September 2020

Published online: 16 September 2020

\section{References}

1. Downs-Canner S, Van der Vliet WJ, Thoolen SJ, Boone BA, Zureikat AH, Hogg ME, et al. Robotic surgery for benign duodenal tumors. J Gastrointest Surg. 2015;19(2):306-12.

2. Yamamoto Y, Yoshizawa N, Tomida H, Fujisaki J, Igarashi M. Therapeutic outcomes of endoscopic resection for superficial non-ampullary duodenal tumor. Dig Endosc. 2014;26:50-6.

3. Nishi T, Kawabata Y, Ishikawa N, Araki A, Yano S, Maruyama R, et al. Intraductal papillary mucinous carcinoma of the pancreas associated with pancreas divisum: a case report and review of the literature. BMC Gastroenterol. 2015;15(1):78.

4. Santi L, Renzulli M, Patti C, Cappelli A, Morieri ML. First case of 2 intraductal papillary mucinous tumors of both ventral and dorsal ducts in pancreas divisum. Pancreas. 2010;39(1):110-1.

5. Participants in the Paris W. The Paris endoscopic classification of superficial neoplastic lesions: esophagus, stomach, and colon: November 30 to December 1, 2002. Gastrointest Endosc. 2003;58(56):S3-43.

6. Yamasaki Y, Uedo N, Takeuchi Y, Ishihara R, Okada H, lishi H. Current status of endoscopic resection for superficial nonampullary duodenal epithelial tumors. Digestion. 2018;97(1):45-51.

7. Abe H, Kubota K, Takayama T, et al. Pancreatic mucin-producing tumor arising in the embryologically dorsal component of the head. Int J Pancreathol. 1998;23(1):77-80. 
8. Hirano $\mathrm{S}$, Kondo S, Ambo Y, et al. Intraductal papillary-mucinous tumors arising in Santorini's duct: clinicopathologic features and treatment of choice. World J Surg. 2005;29:208-11.

9. Saito T, Tsukada T, Boku S, et al. Mucin-producing pancreatic cancer histologically diagnosed by endoscopic biopsu from the minor papilla report of a case. ENDOSC FORUM digest dis. 1989;5(2):281-6.

10. Miyake $H$, lyomasa $S$, Amemiya $T$, et al. A case of invasive carcinoma originating from intraductal papillary-mucinous carcinoma in the accessory duct forming a protruding lesion at the minor papilla. J J.jn Panc Soc. 2004; 19(4):398-403.

11. Kanazumi N, Kanyama Y, Yokoi K, et al. A case of mucin-producing pancreatic cancer arising in Santorini's duct of the pancreas. J Jpn Surg Assoc. 2004;65(5):1356-60.

12. Akashi S, Yamada Y, Sugimori S, et al. Asynchronous intraductal papillary-mucinous carcinoma arising in the accessory pancreatic duct and extrahepatic bile duct carcinoma. Jpn J gastroenterol surg. 2016; 49(11):1141-9

\section{Publisher's Note}

Springer Nature remains neutral with regard to jurisdictional claims in published maps and institutional affiliations.

Ready to submit your research? Choose BMC and benefit from:

- fast, convenient online submission

- thorough peer review by experienced researchers in your field

- rapid publication on acceptance

- support for research data, including large and complex data types

- gold Open Access which fosters wider collaboration and increased citations

- maximum visibility for your research: over $100 \mathrm{M}$ website views per year

At $\mathrm{BMC}$, research is always in progress.

Learn more biomedcentral.com/submissions 